\title{
Statistical Prediction of Extreme Storm Surges Based on a Fully Supervised Weather-Type Downscaling Model
}

\author{
Wagner Costa ${ }^{1,2, *}$, Déborah Idier ${ }^{1}$, Jérémy Rohmer ${ }^{1}$ (D), Melisa Menendez ${ }^{3}$ and Paula Camus ${ }^{3}$ \\ 1 Bureau de Recherche Géologique et Minière (BRGM), 3 avenue C. Guillemin, 45060 Orléans, France; \\ d.idier@brgm.fr (D.I.); j.rohmer@brgm.fr (J.R.) \\ 2 Faculty of Science and Engineering, University of Waikato, 124 Hillcrest Road, Hillcrest, \\ Hamilton 3216, New Zealand \\ 3 Instituto de Hidraulica Ambiental de la Universidad de Cantabria, Parque Científico y \\ Tecnológico de Cantabria, Calle Isabel Torres, 15, Santander, 39011 Cantabria, Spain; \\ melisa.menendez@unican.es (M.M.); paula.camus@unican.es (P.C.) \\ * Correspondence: wc119@students.waikato.ac.nz
}

Received: 27 October 2020; Accepted: 11 December 2020; Published: 16 December 2020

\begin{abstract}
Increasing our capacity to predict extreme storm surges is one of the key issues in terms of coastal flood risk prevention and adaptation. Dynamically forecasting storm surges is computationally expensive. Here, we focus on an alternative data-driven approach and set up a weather-type statistical downscaling for daily maximum storm surge (SS) prediction, using atmospheric hindcasts (CFSR and CFSv2) and 15 years of tidal gauge station measurements. We focus on predicting the storm surge at La Rochelle-La Pallice tidal gauge station. First, based on a sensitivity analysis to the various parameters of the weather-type approach, we find that the model configuration providing the best performance in SS prediction relies on a fully supervised classification using minimum daily sea level pressure (SLP) and maximum SLP gradient, with $1^{\circ}$ resolution in the northeast Atlantic domain as the predictor. Second, we compare the resulting optimal model with the inverse barometer approach and other statistical models (multi-linear regression; semi-supervised and unsupervised weather-types based approaches). The optimal configuration provides more accurate predictions for extreme storm surges, but also the capacity to identify unusual atmospheric storm patterns that can lead to extreme storm surges, as the Xynthia storm for instance (a decrease in the maximum absolute error of 50\%).
\end{abstract}

Keywords: statistical downscaling; weather types; storm surge; fully supervised classification; Xynthia storm; Joachim storm; tide gauge; La Rochelle

\section{Introduction}

Storms, together with tides, are the main driving force for coastal flooding events that have impacted coastal zones throughout history. For example, the years of 1953 and 1962 were marked by strong storm surge events, which, combined with tides, caused flooding over broad coastal areas in the south-western Netherlands and eastern England [1], and in northern Germany [2], respectively. In the last decade, the Xynthia (27 to 28 February 2010) storm severely impacted low-lying coastal areas located in the central part of the Bay of Biscay [3-6], causing 53 fatalities and material damage assessed at more than one billion euros. This event was a mid-latitude storm resulting in a storm surge of about $1.5 \mathrm{~m}$, which coincided with a spring high tide. These examples illustrate the potentially devastating effect that storm surges can have on the coasts and the need for a better prediction of storm surge phenomena. 
Nearshore storm surge is mainly a consequence of atmospheric surges and wave setup [4,7]. Atmospheric surges result from the direct effect of wind (especially in shallow-water) and atmospheric pressure (both in shallow and deep water), while the breaking of waves generates the wave setup. The theoretical model of the inverse barometer (IB) is the simplest way to estimate the storm surge. This approach can be efficient for lands or islands surrounded by deep seas, however, most of the time this is not sufficient, because it does not account for the local and regional effect of the wind [8], neither for the wave set up contribution [4,7]. In addition to the IB approach, there are mainly two types of methods to estimate storm surges: dynamical approaches such as dynamical downscaling (DD) and data-driven approaches such as statistical downscaling (SD). Advantages and disadvantages between DD and SD approaches were discussed for the specific case of waves on the coast of France [9]. They concluded that there is a balance between representing physical processes and statistical relationships; the first are limited by computational time and resources, the latter are faster but have a limited ability to explain all the physical processes.

The DD relies on the use of numerical models solving physical equations, for instance, the shallow-water equations. Generally, DD allows a good representation of physical processes with a high resolution both in time and space; however, they need data for boundary and forcing conditions (e.g., observed or regional model outputs for wave parameters, water level, tidal constituents, wind magnitude, and direction, see for instance [4]) and the simulations can demand a high computational effort $[10,11]$. In addition, precise local modeling requires the availability of good bathymetric data and sometimes complex modeling techniques. For instance, if the wave setup is expected to play a significant role, then the numerical modeling should rely on two coupled models: one focusing on the atmospheric storm surge, most of the time using shallow-water equation models, and another focusing on waves and the resulting wave setup using a spectral wave model $[4,7]$.

The SD establishes a statistical link between the predictor (e.g., averaged regional atmospheric data such as sea level pressure, SLP) and the predictand (e.g., measured or simulated storm surge or wave parameters for a given point). SD approaches present good approximations in terms of the statistical distribution of the variable to be predicted with few input variables, but usually have limitations when applied to short-term predictions (e.g., minutes and hours) and extreme events [12-16]. For example, an SD method based on a multiple linear regression linking principal components of atmospheric data to local modeled atmospheric surge levels was used to reconstruct historical daily maximum storm surge (SS) on a global scale from 1871 to 2010 [14]; and also applied for the specific case of southeast Asia [15] and New Zealand [16].

Another example of an SD method is the weather-type approach, which has been widely used for estimating wave parameters as well as storm surge and wave parameters combined. This technique has been mainly used to investigate climate-related variability and future projections, analyzing monthly and annual distributions [9,17-19]. In these studies, the principal components of the predictor are clustered, resulting in different groups of data, called weather types (WT). An improvement of this method is the weather type regression guided approach [12]. It works as the former method, but, in the clustering process, information on the predictand is included in addition to the predictor variable (SLP and sea level pressure gradient (SLPG)) through a weighting scheme (via an $\alpha$ factor).

Other SD methods that rely on machine learning algorithms have been applied for the estimation of storm surge. For instance, the artificial neural network algorithm has been used for short-term local predictions associated with severe storms, such as hurricanes [20-26], as well as for the study of extreme events on a global scale [27]. The random forest algorithm has also been used for the estimation of global SS and compared with DD approaches, showing that data-driven methods can perform equally or better on storm surge predictions than dynamical models on a global and long-term scale [28].

Although the SD models were applied to a large range of locations around the world with good efficiency, the predictions for enclosed seas and bays, where the geographical settings can play an important role, are sometimes not as satisfactory as for exposed coastlines, especially for maximum value daily predictions $[12,14,16,18,19]$. Another limitation is that despite the fact the multiple linear 
regression approach presents good approximations for daily predictions [14-16], it does not establish an easy visualization and direct link between the WTs and local storm surge response; while the SD weather types approach can do it, but is not originally designed for daily predictions. The design of SD models based on the WT approach requires the defining of several key elements, which can vary accordingly to the study site, spatial-temporal scale, and target variable of the prediction (in this manuscript, SS). Some of these elements are the weather type's selection method and the configuration of the predictor, by setting the appropriate variable and spatial-temporal domain.

The present study aims to: (1) build a WT-based method to set up a statistical downscaling model to estimate the daily maximum value of storm surge, and (2) estimate the added value in comparison with other models. For this development, we focus on predicting the storm surges at the La Rochelle-La Pallice tide gauge (France). For instance, we will show how our SD model can provide valuable information on the atmospheric patterns of storms responsible for the extreme daily values of local storm surges.

\section{Study Site and Database}

La Rochelle is located along the south-west coast of France, New Aquitaine, in the maritime region called the Bay of Biscay, as shown in Figure 1. It is located at the inner shelf, protected by swells due to the presence of Ile de Ré and Ile d'Oléron. This implies that the average and extreme events of storm surges (e.g., Xynthia, 2010) that occurred in this area do not result only from the inverse barometric effect, but also from the wind effect and regional wave setup [3,4]. The choice of La Rochelle as our study site aims at ensuring a minimum level of complexity in the surge signal. There is one tidal gauge (La Rochelle-La Pallice) and a weather station, operated by SHOM (Service Hydrographique et Océanographique de la Marine) and Météo-France, respectively.

To set up our statistical models, which aim to predict SS for La Rochelle-La Pallice, we need to define a predictor and predictand data (see Sections 3.1 and 3.2 for more details). For the predictor definition process, we use the atmospheric CFSR and CFSRv2 reanalysis data [29-31] over the 1979 to 2014 period. These datasets have a spatial resolution of $0.33^{\circ}$ and $0.22^{\circ}$. Here, we used the following hourly output data: sea level pressure (SLP), wind magnitude (WND), and geopotential height at $500 \mathrm{hPa}(\mathrm{GP})$. In addition, to investigate the effect of the spatial domain of the predictor, these variables were extracted onto the domain of the North Atlantic (NA) and northeast Atlantic (NEA) zones, Figure 1A.

The predictand data is derived from the water level measured at La Rochelle-La Pallice (available at data.shom.fr, tidal gauge station doi: 10.17183/REFMAR\#34). First, the observed storm surge dataset is estimated by subtracting the predicted tide provided by the SHOMAR software [32] to the water level measurements, resulting in a time-series covering the period from 1941 to 2014 . Due to the many data gaps in the records before 2000, we focus on the 2000 to 2014 period, for more reliable results. Thus, the time-series is post-processed to extract the maximum storm surge per day (i.e., SS), defining the predictand data. Figure 2 presents the respective dataset, showing extreme storm surges exceeding $1 \mathrm{~m}$, with the largest value ( 1.5 m) observed on 28 February 2010, corresponding to the Xynthia event.

This outstanding storm has unique aspects. According to previous numerical modeling work [3], the unusual trajectory from SW to NE enables the storm to produce short waves that significantly enhanced the atmospheric storm surge at La Rochelle-La Pallice, which represented about $94 \%$ of the Xynthia storm surge, the rest being induced by the regional wave setup [4]. This proportion depends on the characteristics of the storm. For instance, for the Joachim storm (15 to 16 December 2011), the relative contribution of the atmospheric storm surge to the surge was smaller (88\%) (deduced from the results of [4]), highlighting the non-negligible effect of the regional wave setup on surges in such environments. 


\section{A}
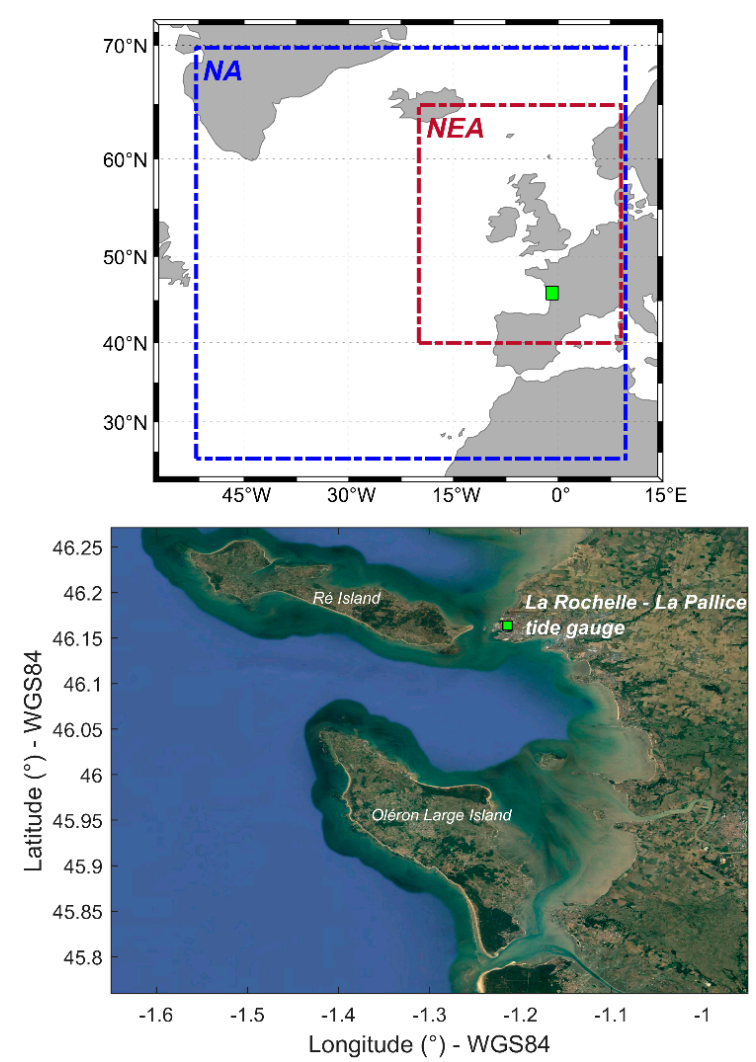

B

Figure 1. Study site: La Rochelle. (A) Study site location and North Atlantic domain (NA) and northeast Atlantic domain (NEA). (B) Regional setting.
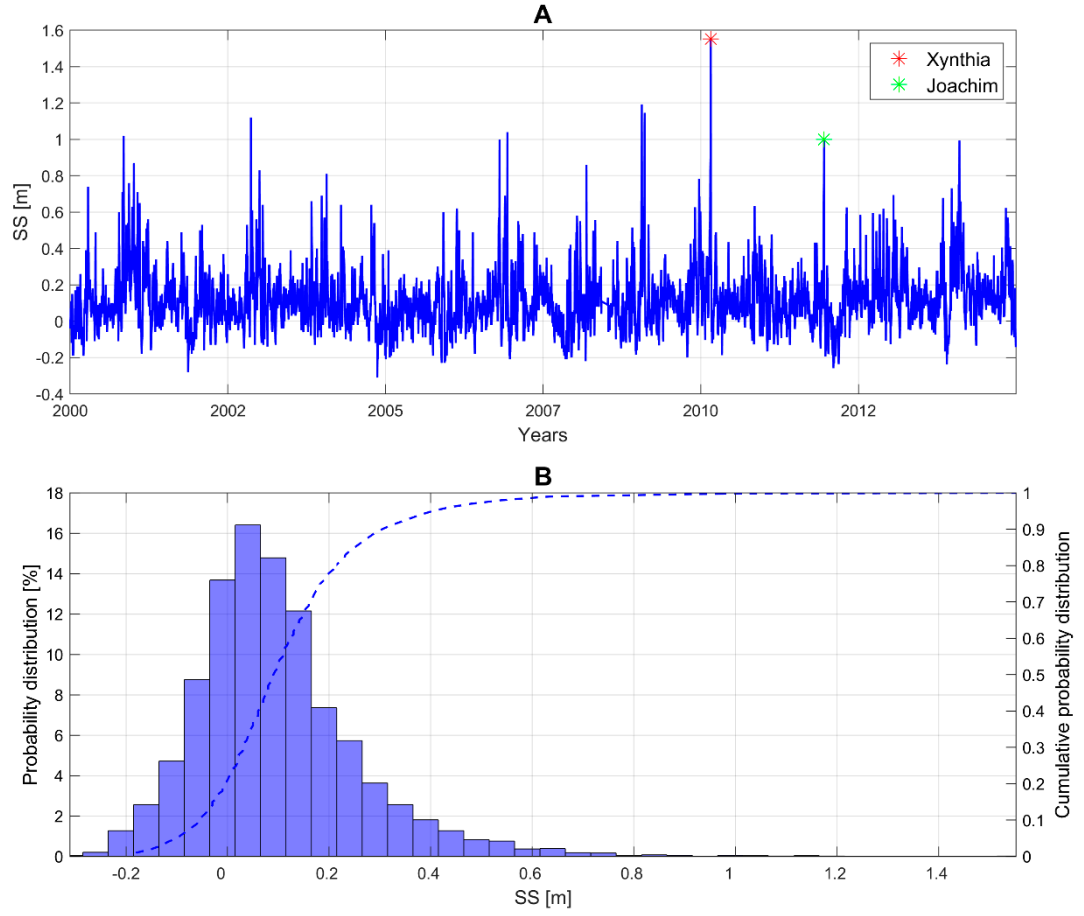

Figure 2. (A) Daily maximum storm surge (SS) time series at La Rochelle-La Pallice tidal gauge from 2000 to 2014 and the extreme events of Xynthia (February 2010) and Joachim (December 2011). (B) Descriptive probability distribution (bars) and cumulative probability of SS (dashed line). 


\section{Methods}

Here, we first give a general explanation of the statistical downscaling weather type approach (Section 3.1). Second, we describe the sensitivity tests made (e.g., on predictors selection, clustering technique) to identify the optimal configuration for the proposed SD (Section 3.2). Third, we describe the alternative predictive models (e.g., formers SD multiple linear regression and SD WT models) whose performances are compared with the optimal model resulting from set-up sensitivity tests (Section 3.3).

\subsection{A Generalized Explanation of the Weather Type Approach}

As already introduced (Section 1), the statistical downscaling weather types approach is based on the establishment of a statistical relationship between regional atmospheric data, i.e., predictor, and local response of a given marine variable (e.g., wave parameter and/or storm surge) which is the target of study, i.e., predictand. Figure 3 illustrates the main steps. The arrows and numbers indicate the flow and steps of the method, respectively. This figure is a generalization of the WT approaches applied for the wave climate prediction [13], and combined wave and storm surge climate [12]. In what follows, we detail each step, based on these past studies, while the application of this general framework to SS prediction is detailed in Sections 3.2 and 4.1.

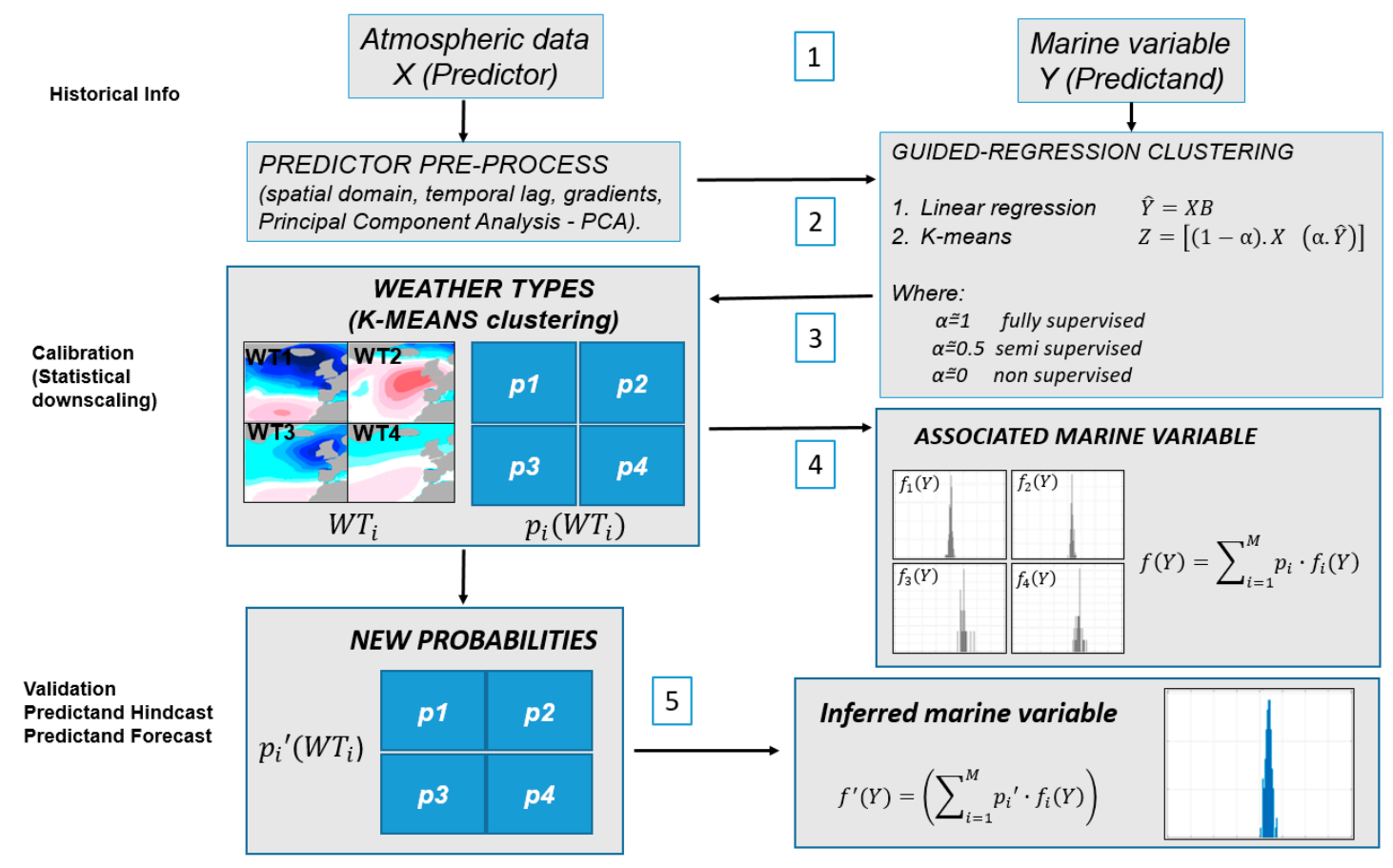

Figure 3. General chart flow of WT-based statistical downscaling approach. The numbers (1 to 5) indicate the main steps of the method. The $p$ and $p^{\prime}$ are the probabilities of each weather type (WT) during the calibration and validation periods, respectively. The $f(Y)$ and $f^{\prime}(Y)$ are the probability density functions of the predictand in the calibration and validation period, respectively.

Accordingly, with [12] this method is composed of the following steps: (1) collecting of historical data for the predictor and predictand followed by pre-processing; (2) performing a regression-guided classification (first, a multiple linear regression between predictand and predictor, and second, a classification of the predictor and the estimations of the predictand); (3) defining the weather types of the synoptic circulation conditions; (4) establishing the statistical relationship between predictor and predictand (empirical distribution functions of SS are calculated for each WT); (5) validating the statistical model or applying the model to different temporal periods. 
First, the pre-processing of predictor and predictand historical data need to be executed. For the European Atlantic coast, former works $[14,16,20]$ used as predictors variables SLP and SLPG fields covering an area from $20^{\circ}$ to $80^{\circ} \mathrm{N}$ and from $60^{\circ} \mathrm{W}$ to $50^{\circ} \mathrm{E}$ of the North Atlantic basin; while the predictand data used were daily mean wave parameters and storm surge. The predictor's domain area was defined by the evaluation of source and travel time of wave energy reaching a local area (ESTELA) method, which shows that for the most part, the wave energy that reaches the European coast takes three days to travel from the genesis point $[33,34]$.

Then, for the cases of wave climate prediction [12,13], the predictor is defined as the three-day mean SLP and three-day mean SLPG, calculated every day through the historical time period. Thus, the predictor associated with a certain day corresponds to the average obtained using the same day and the previous two days. This process aims to reduce the dimensionality of the data and also takes into account the time response between the atmospheric system and the consequent storm surge. A principal components analysis (PCA) is applied to the predictor in order to reduce the dimensionality of the data and simplify the classification process. From all the principal components (PCs) identified, just the ones which together explain 95\% of the data variance are selected [13].

Second, the regression-guided classification is performed. To start with, a multivariate regression between predictors PCs and predictand daily data is developed, resulting in predicted marine variables. The predicted data is then concatenated with the PCs in a new matrix, structured just as shown in Figure 3, step 2 (for details on this procedure see [12]). Thus a K-means algorithm (KMA) is applied to the concatenated matrix (step 3), dividing the data space into a number of clusters, each one defined by a prototype and formed by the data for which the prototype is the closest [35]. The number of clusters should be pre-defined, which is 100 in former studies applying this approach for the North Atlantic region $[12,13]$. The maximum-dissimilarity algorithm (MDA) is performed to initiate the prototypes, which guarantees a deterministic classification and the most representative initial subset. The level of influence between atmospheric and marine variables (predictor and predictand, respectively) in the classification is controlled by a weighting factor $\alpha$ [36]. In the case $\alpha=0$, an unsupervised multivariate regression classification is applied; for $\alpha=\sim 0.5$, a semi-supervised multivariate regression-guided classification is applied; and for $\alpha=1$, a fully supervised classification is performed.

Still, in the third step, the WTs are calculated as the mean of the synoptic circulation conditions (i.e., cluster center) included in each cluster of the regression-guided classification. The statistical relationship between the predictor and the predictand is established in the fourth step: the empirical probability distributions of daily local marine variables are calculated for each $W T\left(f_{i}\right)$, following the equation in Figure 3, step 4, considering the probabilities (p) of each WT and their associated distribution during a given calibration period. In the fifth step, given a validation period, the predictand is predicted where $\mathrm{p}_{\mathrm{i}}$ is the probability of the $\mathrm{WT}$ in the validation period $\left(\mathrm{WT}_{\mathrm{i}}\right)$.

\subsection{Procedure for Identifying the Best SD Using WT Approach Configuration}

In order to set up a statistical downscaling model of SS for La Rochelle-La Pallice tidal gauge station, we follow the general procedure (Figure 3) and first perform sensitivity tests to identify the best configuration of the model (called SD1). The tests are done by varying each parameter presented in Table 1, one at a time.

To evaluate the influence of different spatial domains of weather patterns, two predictor domains were used (Figure 1): the North Atlantic (NA) and northeast Atlantic (NEA). Indeed, modeling experiments suggest that the atmospheric storm surges at La Rochelle are driven by the NEA meteorological patterns [5,37], while the regional wave setup is related to swells whose generation domain extends to the NA domain [4]. The spatial resolution of the predictor is another important factor in the downscaling technique. Thus, the CFRS $\left(0.33^{\circ}\right)$ and CFRSv2 $\left(0.22^{\circ}\right)$ data were linearly interpolated at three different resolutions $\left(0.5^{\circ}, 1^{\circ}, 2^{\circ}\right)$ in the predictor's domain.

There is a time lag between the atmospheric condition and its local storm surge response, which can vary on a scale of days $[12,13,34]$. As explained in Section 3.1 , this is taken into account 
by calculating the $\mathrm{X}$-day average predictor variable, calculated every day through the historical time period. Thus, the predictor associated with a certain day corresponds to the average obtained using the same day and the previous $n$ days $(X$-day average $=($ certain day $+n$ days $) /(n+1))$. We tested $\mathrm{X}=2,3$, and 4 day-average as the predictor variable.

Table 1. The different set-ups were tested in the sensitivity analyses. The bold parameters are the parameters used in the optimal model, SD1, after Section 4.1.

\begin{tabular}{cc}
\hline ID Test & Parameter Values \\
\hline Domain & North Atlantic, Northeast Atlantic \\
Spatial Resolution & $2^{\circ} ; \mathbf{1}^{\circ} ; 0.5^{\circ}$ \\
Number of Days Averaged for the Predictor Definition & $\mathbf{2 , 3} 4$ days \\
Type of Clustering & KMA, SOM \\
$\alpha$ & $0.2,0.6,0.8, \mathbf{1}$ \\
& Daily Min. SLP and Daily Max. SLPG; \\
Predictor Variable & Daily Min. SLP and Daily Max. WND, \\
& Daily Mean GP, \\
& Daily Max. GP, \\
\hline
\end{tabular}

In order to determine the weather types, a clustering technique is applied. For this purpose, we tested the usual KMA approach and the so-called self-organizing maps (SOM) [38]. For evaluating the effect of semi-supervised versus fully supervised classification on model performance, $\alpha$ parameter values of $0.2,0.6,0.8$, and 1 were tested. In all the cases tested, a number of 100 clusters was pre-determined to start the clustering algorithm based on former studies using the WT approach for the North Atlantic region [12,13].

Regarding the predictor variables, the most common approach is to use SLP and SLPG. However, other atmospheric variables could be considered as relevant predictors for storm surges like wind magnitude at $10 \mathrm{~m}$ above the sea surface (WND) and the geopotential height of the $500 \mathrm{hPa}(\mathrm{GP})$. Thus, we investigated the following predictor variables: daily minimum SLP and daily maximum SLPG; daily minimum SLP and daily maximum WND; daily mean GP; daily maximum GP.

The model performances are evaluated in terms of root mean squared error (RMSE, Equation (1), with $n$ number of days), maximum absolute error (MAE, Equation (2)), and r-squared (R2, Equation (3)), compared with the observed SS. The error indicators are calculated for every year and also averaged over the five years of the validation period $(\overline{R M S E}, \overline{M A E}, \overline{R 2})$ and described as follows:

$$
\begin{gathered}
R M S E=\sqrt{\sum_{i=1}^{n} \frac{\left(S S_{\text {simulated }}-S S_{\text {measured }}\right)^{2}}{n}} \\
M A E=\max \left\{{ }_{i=1}^{n}\left|S S_{\text {simulated }}-S S_{\text {observed }}\right|\right\} \\
R^{2}=1-\frac{\sum\left(S S_{\text {simulated }}-S S_{\text {measured }}\right)^{2}}{\sum\left(S S_{\text {measured }}-\overline{S S_{\text {measured }}}\right)^{2}}
\end{gathered}
$$

Thus, for each configuration, Table 1 , the model is calibrated using 14-year-long data from the 15-year dataset (2000 to 2014). The remaining one-year-long period is used for validation purposes, following a leave-one-year-out cross-validation. This procedure is done for five individual years ( $K=2010$ to 2014).

\subsection{Comparing the Best Model Configuration with Former Models}

With the aim to compare the performance of the optimal model (SD1, Sections 3.2 and 4.1) with the alternative prediction methods based on former approaches, several tests were performed (see Table 2). For all the tests, we keep a spatial resolution of $1^{\circ}$ in the NA domain and use the same validation procedure as in Section 3.2. 
Table 2. Configuration of each model tested in sensitivity analyses.

\begin{tabular}{|c|c|c|c|c|c|c|c|}
\hline ID Test & Type of Model & Predictor & Predictand & $\begin{array}{c}\text { Calibration } \\
\text { Period }\end{array}$ & $\begin{array}{c}\text { Validation } \\
\text { Period }\end{array}$ & $\begin{array}{c}\text { Type of } \\
\text { Clustering }\end{array}$ & Reference \\
\hline SD2 & $\begin{array}{c}\text { Statistical multiple } \\
\text { linear regression model }\end{array}$ & $\begin{array}{l}\text { Two-days mean of } \\
\text { daily mean SLP; } \\
\text { Two-days mean of } \\
\text { daily mean SLPG }\end{array}$ & \multirow{3}{*}{$\begin{array}{c}\text { Daily maximum } \\
\text { storm surge (SS) } \\
\text { observed at La } \\
\text { Rochelle-La } \\
\text { Pallice tide gauge }\end{array}$} & \multirow[t]{3}{*}{ 2000-2014 } & \multirow{3}{*}{$\begin{array}{l}\text { Leave-one } \\
\text { year-out } \\
\text { cross-validation } \\
\text { 2010-2014 }\end{array}$} & No clustering & Cid et al (2017) [14 \\
\hline SD3 & $\begin{array}{c}\text { Statistical downscaling } \\
\text { WT, semi-supervised } \\
\text { regression. }\end{array}$ & $\begin{array}{l}\text { Two-days mean of } \\
\text { daily mean SLP; } \\
\text { Two-days mean of } \\
\text { Daily Mean SLPG }\end{array}$ & & & & $\begin{array}{c}\text { KMA } \\
\text { semi-supervised } \\
(\alpha=0.6)\end{array}$ & $\begin{array}{c}\text { Camus et al (2016) } \\
{[12]}\end{array}$ \\
\hline SD4 & $\begin{array}{l}\text { Statistical downscaling } \\
\text { WT, no supervised } \\
\text { regression }\end{array}$ & $\begin{array}{l}\text { Two-days mean of } \\
\text { daily mean SLP; }\end{array}$ & & & & $\begin{array}{l}\text { KMA no guided } \\
\text { regression }\end{array}$ & $\begin{array}{c}\text { Camus et al (2014) } \\
{[13]}\end{array}$ \\
\hline IB & Theoretical model & - & & - & - & No clustering & Inverse barometer \\
\hline
\end{tabular}


The SD2 is a statistical downscaling model based on multiple linear regression [14]. It does not estimate the statistical relation between classified weather types and the daily maximum surge level (SS) but, instead, directly fits a multiple linear regression model between PCs of the atmospheric predictor and SS. Thus, the daily maximum surge level at a given location (xi) holds as follows:

$$
\begin{gathered}
\text { daily max. surge }(x i, t)=a_{i}+b_{1, i} \times P C(1)(x i, t)+b_{2, i} \times P C(2)(x i, t)+\ldots+ \\
b_{p n, i} \times P C(p n)(x i, t)
\end{gathered}
$$

where $p n$ is the number of PCs of atmospheric data that explains $95 \%$ of the variance, $a_{i}, b_{1, i}, b_{n, i}$ are the coefficients obtained in the regression model. As the predictor, SD2 uses the two-day mean of daily mean SLP and SLPG.

The SD3 and SD4 are weather type statistical downscaling methods based on semi [12] and non-supervised classification [13], focused on combined wave and storm surge climate and on wave climate predictions, respectively (see Figure 3, step 2). Here, these methods are adjusted to predict the SS: the daily maximum observed storm surge is set as the predictand variable instead of the daily average of wave parameters. As the predictor, SD3 and SD4 use the two-day mean of daily mean SLP and SLPG.

The IB model (for inverse barometer) is based on the relation between local pressure variations $\left(\Delta \mathrm{P}_{\mathrm{A}}\right.$ in units) around the mean atmospheric pressure $\left(\overline{P_{A}}\right.$ in $\left.\mathrm{hPa}\right)$ over the oceans and the local changes in sea-level $(\Delta \zeta)$, expressed by Equation (5), where $\rho$ is the salt-water density $\left(\mathrm{kg} / \mathrm{m}^{3}\right)$ and $\mathrm{g}$ is the acceleration of gravity $\left(9.8 \mathrm{~m} / \mathrm{s}^{2}\right)$.

$$
\Delta \zeta=-\Delta \mathrm{P}_{\mathrm{A}} / \rho g
$$

In the present study, the analysis of the local measurements at the meteorological station in La Rochelle (Meteo France), provides a mean sea level pressure $\left(\overline{P_{A}}=1017 \mathrm{hPa}\right)$.

Finally, it is important to remark that the comparison between the SD1 model and the alternatives should not be seen as an absolute statement, but only as an estimation of the method skills for predicting SS, on a site like La Rochelle-La Pallice.

\section{Results}

The results are described in the subsections below. First (Section 4.1), we present the results regarding the comparison between different configurations of the SD using WT approach, following the procedure explained in Section 3.2. Second (Section 4.2), the best model's configuration is compared with former models as described in Section 3.3. Third (Section 4.3), we compare the different WT classifications performed by the optimal configuration and other WT based models (SD3 and SD4).

\subsection{Comparing Different SD Based on WT Approach Configurations}

The results of the sensitivity tests for different model set-ups for the five validation years ( $K=2010$ to 2014) are summarized in Figure 4, in terms of $\overline{M A E}$. Similar results are reached by considering the other performance criteria (Table A1). Each arch refers to a parameter tested, which was varied one at a time with respect to the SD1 configuration (identified as the optimal model). Several observations can be made.

First, the use of the North Atlantic domain (NA) shows better results (i.e., lower MAE) than the northeast Atlantic domain (NEA). This highlights the importance of large-scale patterns in the atmospheric predictor, since the NA domain does not only include the area of the atmospheric surge genesis but also the swell generation zone which produces the regional wave-setup in the surrounding of La Rochelle.

The $1^{\circ}$ resolution has the best performance, showing that the relation between the error and the spatial resolution is not monotonic: the highest resolution $\left(0.5^{\circ}\right)$ leads to the largest error values $\left(\overline{R M S E}=0.09 ; \overline{M A E}=0.57 \mathrm{~m} ; \overline{R^{2}}=0.69\right)$; and similarly, the coarser resolution $\left(2^{\circ}\right)$ performs poorly $\left(\overline{R M S E}=0.08 ; \overline{M A E}=0.50 \mathrm{~m} ; \overline{R^{2}}=0.77\right)$, as can be observed in Figure 4 and Table $1 \mathrm{~A}$ in Appendix A. 


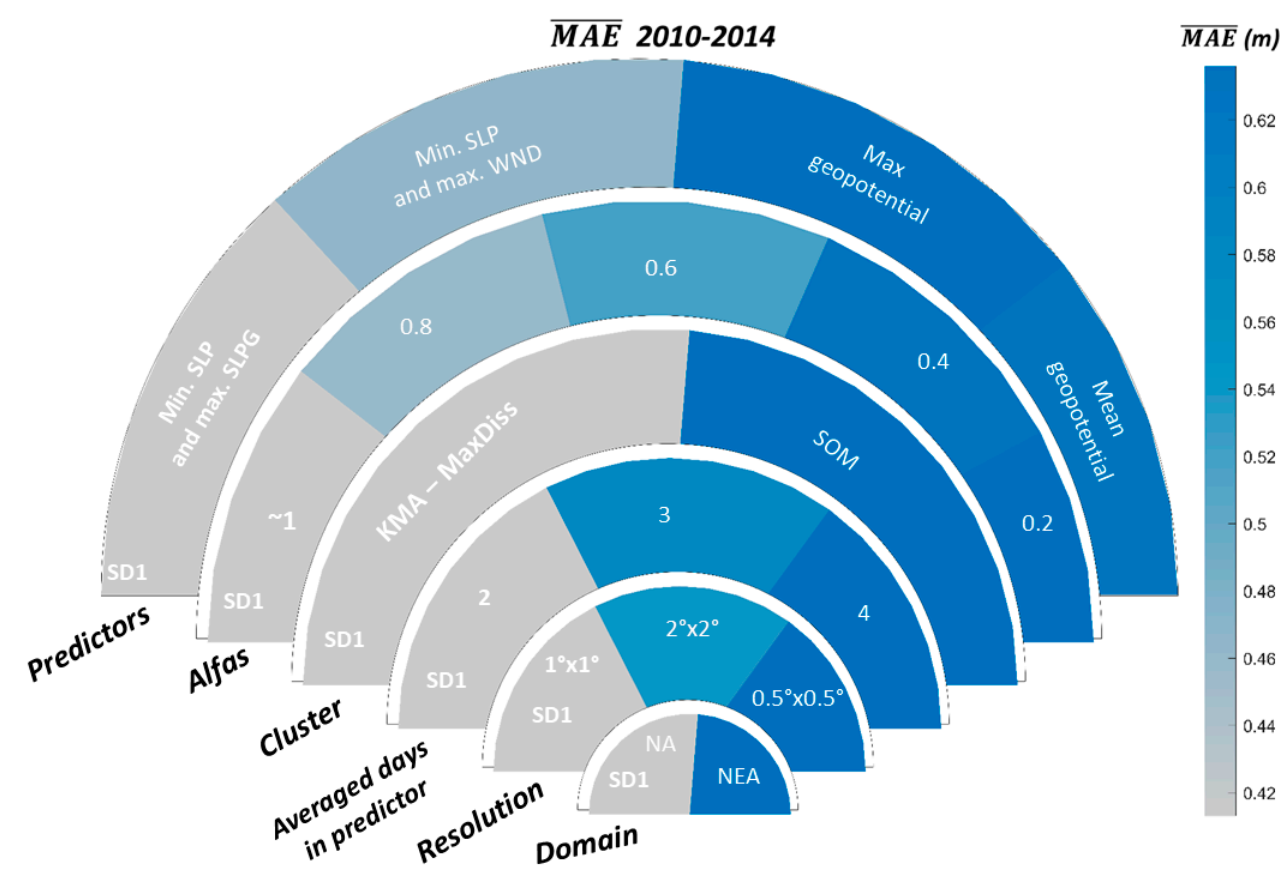

Figure 4. $\overline{M A E}$ of four validation years (2010 to 2014) for the optimal configuration (SD1) and the other different set-ups of the sensitivity tests described in Table 1.

One possible explanation is that the increase in the predictor dimensionality can worsen the performance of the clustering step, i.e., the identification of the WTs. This relies on the fact that PCA is applied in this method to reduce the dimensionality of the dataset by removing redundant data in means of variance in the spatial and temporal domain (e.g., strongly correlated data), thus allowing the clustering algorithm to improve its performance. The predictor dimensionality is 1364,5580 , and 21,894 for the $2^{\circ}, 1^{\circ}$, and $0.5^{\circ}$ spatial resolutions, respectively, which are transformed to 64,82 , and 98 PCs, which explains $95 \%$ of the data variance. This shows that a higher resolution requires more PCs to explain the same percentage data variability and that predictor dimensionality increases with spatial resolution, but this does not imply better model performance. Indeed, for too high resolution, there could remain too much redundant data ("noise"), while, for too low resolution, the variability may not be sufficiently captured. Thus, there should be an optimal resolution for properly describing the variance, but avoiding too much redundant data. In addition, we should highlight that the local predictand (storm surge) is a response to the atmospheric conditions but also to local bathymetry and coastal morphology. These local processes are not related to the synoptic circulation. Therefore, the introduction of more detailed information about the atmospheric conditions does not necessarily improve the skill of the downscaling method. Regarding the number of days used to define the predictor, the model performance is improved by using the two-day average. This last aspect will be discussed in more detail in Section 5 .

Concerning the clustering process, the use of the KMA algorithm shows a better capability than SOM to predict the daily maximum surge (further discussion in Section 5). Furthermore, the fully supervised regression guided classification $(\alpha=1)$ shows an outstanding improvement of the predictions, principally in terms of $\overline{M A E}$, when $\alpha$ increases, $\overline{M A E}$ decreases to $0.41 \mathrm{~m}(\alpha=1)$. The other error metrics exhibit similar behavior, with $\overline{R M S E}\left(\overline{R^{2}}\right)$ decreasing (increasing) as $\alpha$ values increase (leading to $\overline{R M S E}=0.07$ and $\overline{R^{2}}=0.78$ for $\alpha=1$ ).

Finally, the combination of the two-day mean daily minimum SLP and two-day mean daily maximum SLPG as predictors leads to the best surge predictions in La Rochelle. By using these predictors, we account for both the intensity of the storms and their dynamics. This builds a more heterogeneous dataset for the clustering process. This ensures the identification of the extreme weather patterns responsible for the maximum storm surge at the coast. 


\subsection{Performance Comparison with Alternative Prediction Approaches}

The overall performance of the tested models is estimated by analyzing $\overline{R M S E}$ and $\overline{M A E}$ (the averaged RMSE and MAE errors for the five validation years 2010 to 2014), as shown in Figure 5. SD1 exhibits the best results $(\overline{R M S E}=\sim 0.07 \mathrm{~m}$ and $\overline{M A E}=\sim 0.4 \mathrm{~m})$. Although SD2 exhibits a similar $\overline{R M S E}$, it presents a worse $\overline{M A E}(\sim 0.55 \mathrm{~m})$. SD3 shows similar results compared with SD2, while SD4 and IB models exhibit the worst performances.

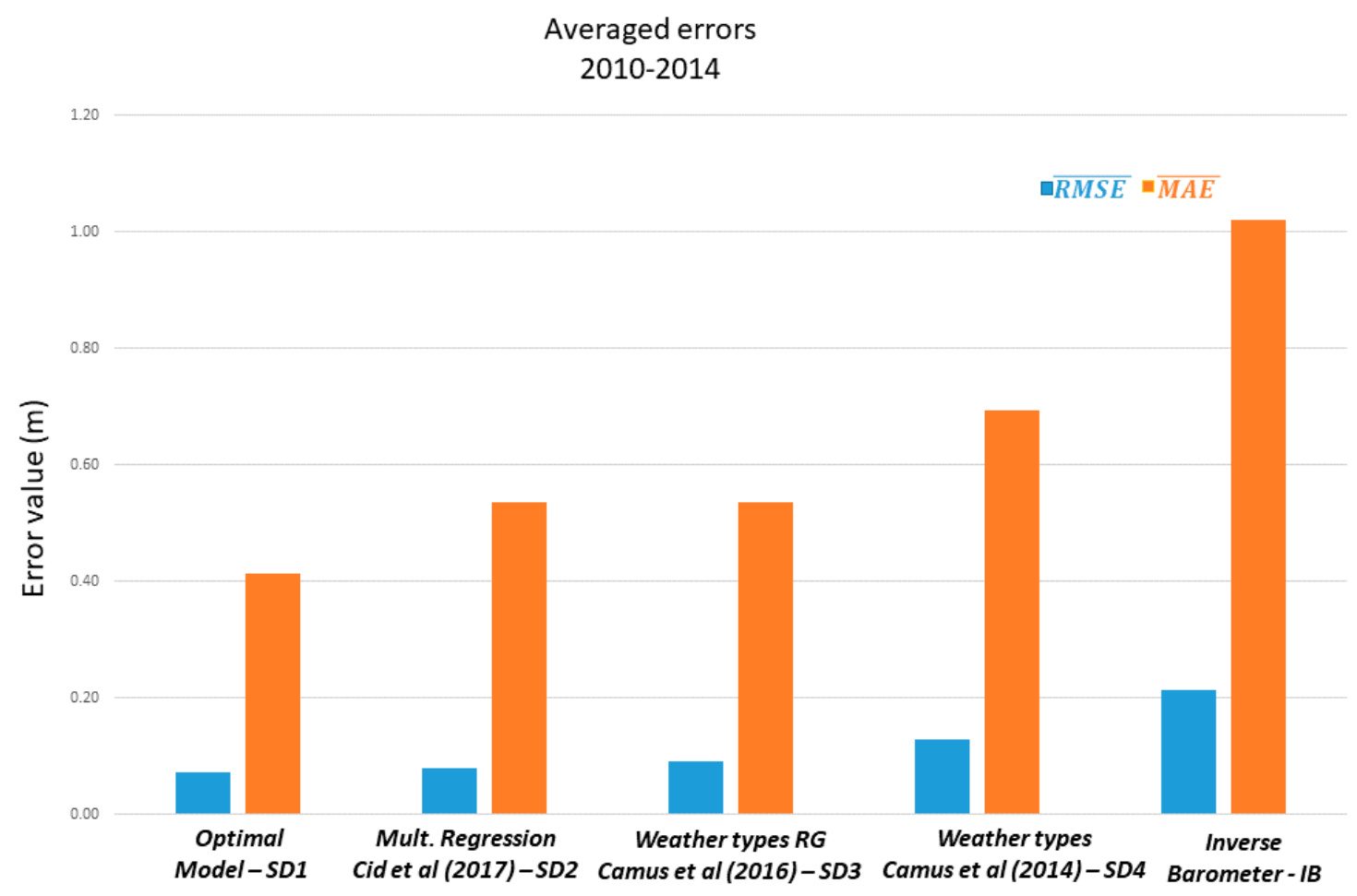

Figure 5. Average error values ( $\overline{R M S E}$ and $\overline{M A E})$ for validation years 2010 to 2014 .

To better illustrate the models' performances, we analyze the different validation years separately. For example, Figure 6 presents the results (observed and modeled SS time series, scatter plot, and errors) for the 2010 validation year, which contains the maximum observed storm surge value of $\sim 1.5 \mathrm{~m}$ (Xynthia storm, 28 February 2010). For each model, the MAE corresponds to the error in predicting the Xynthia SS. The optimal model (SD1) has the best fit with the measured data in terms of RMSE $=0.07 \mathrm{~m}, \mathrm{MAE}=0.5 \mathrm{~m}$ and $\mathrm{R}^{2}=0.8$. The multiple linear regression model (SD2) also shows a good approximation with similar values of RMSE $(0.09 \mathrm{~m})$ and $\mathrm{R}^{2}(0.7)$, but with a worse value of MAE $(1.08 \mathrm{~m})$, corresponding to a $58 \mathrm{~cm}$ larger underestimation of the Xynthia SS. This reinforces that using extreme daily predictor values (i.e., min SLP and max SLPG), with a fully supervised regression guided clustering, can improve the prediction performance, in particular of the upper tail of the predicted data distribution, i.e., rare and extreme events.

The inverse barometer model (IB) provides the worst results, as expected since this model only computes the local variations in sea level pressure, ignoring the action of regional weather patterns, wind stress, and waves. The SD4 model provides a better approximation than IB by including regional atmospheric patterns, but it is not capable of properly representing the distribution of SS since the weather pattern and predictand data are not directly linked statistically during the clustering step (i.e., non-supervised classification). This is improved in the SD3 as this model clusters a concatenated matrix composed of weather patterns (PCs) and predictand data, by applying a semi-supervised classification (see Figure 3, step 3). 

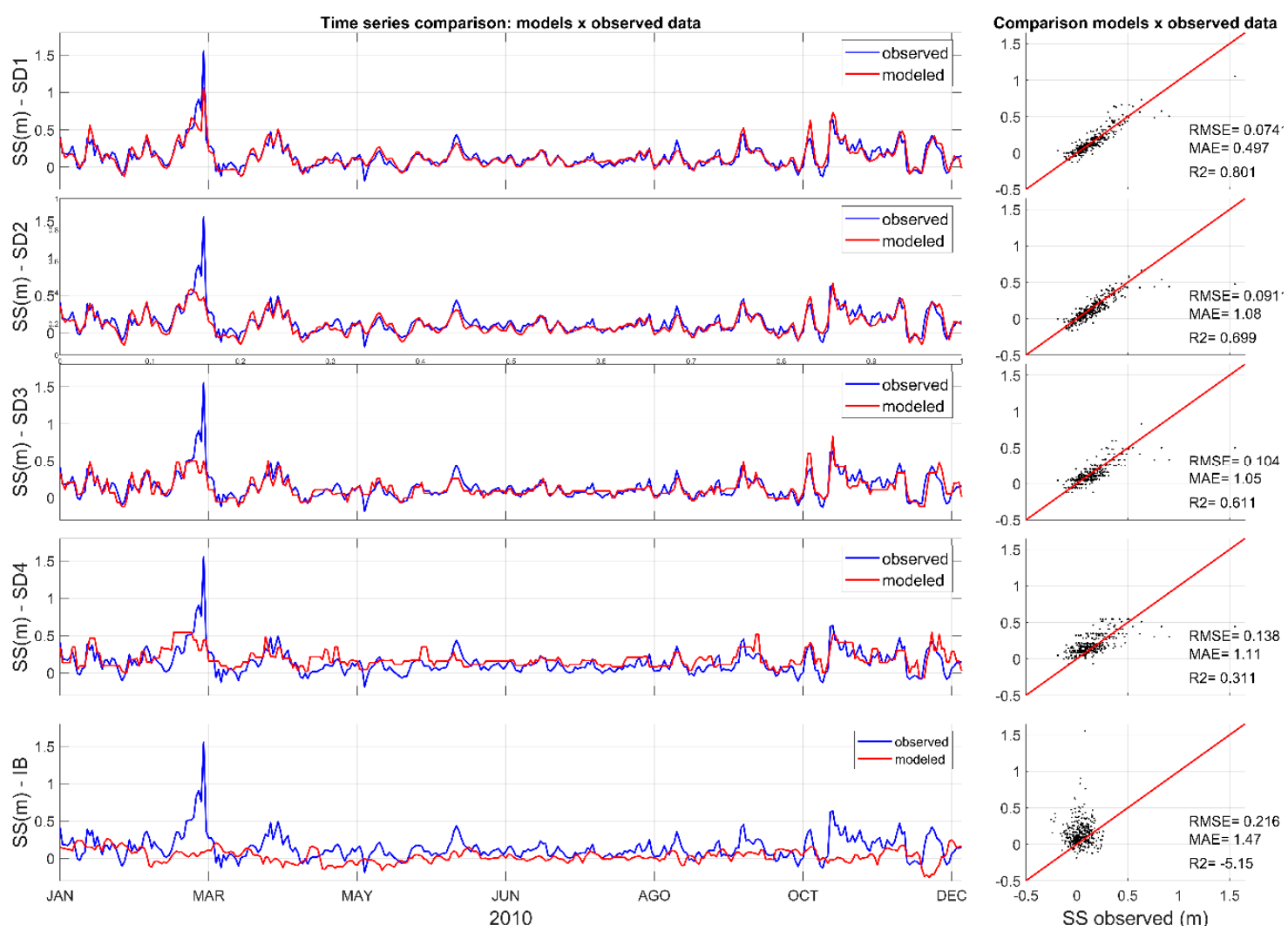

Figure 6. Comparison of the performance of the different downscaling approaches described in Table 2.

Validation year: $\mathrm{K}=2010$.

\subsection{Weather Types and Storm Surges in La Rochelle}

The use of a fully supervised regression guided classification in the SD1 model has shown good performance in identifying both regional and local synoptic patterns associated with average and extreme events of storm surge at La Rochelle. This is illustrated in Figure 7, which shows the daily minimum SLP fields associated with each of the 100 weather types classified during the calibration period from the years 2000 to 2014 and validation period $K=2012$. As observed, most of the WTs are associated with positive surge daily maximum values, while few others have negative surge values distributions, corresponding to the action of the high-pressure areas. It should be noted that the Xynthia and Joachim storms fall in the weather types WT38 (red rectangle) and WT70 (green rectangle), respectively.

The atmospheric regional patterns can be identified as patterns that spread all over the domain and, in some cases, exhibit centers of low and high pressure clearly defined by an accentuated SLP gradient (e.g., WT2, WT11). On the other hand, there are patterns not so well defined (e.g., WT41, WT86), which are usually related to more frequent events, and lower atmospheric gradient. Regarding the local synoptic patterns, they can be easily recognized by the accentuated gradients and centers of low and high sea level pressure covering an area from the United Kingdom to the Bay of Biscay including the English Channel (e.g., WT51, WT25).

Observing Figure 8, which shows the SS distribution associated with the corresponding WT, it can be seen that the highest storm surge values are linked with low-frequency weather types, with regional (WT75, WT76) and local patterns (WT6, WT21). Sometimes these WTs occur only once over the whole calibration period as in the case of the Xynthia storm (2010), represented by WT38 which looks like a local storm. Note that the Joachim (2011) storm is also well represented by WT70, showing a regional scale weather pattern, which highlights the model's capability to recognize both regional and local extreme storms. 


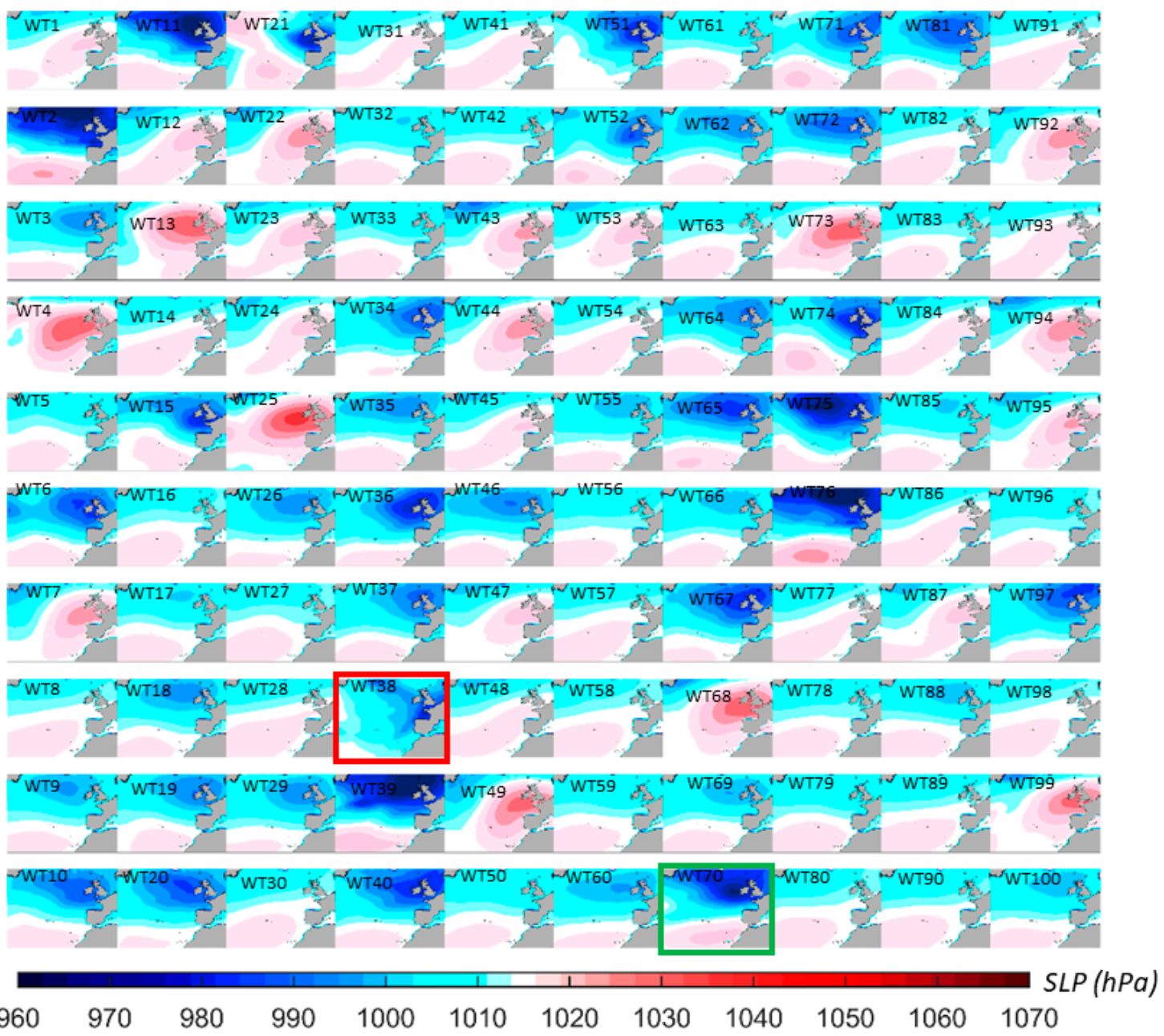

Figure 7. Daily minimum SLP associated with each of the 100 weather types of the SD1 model, using a fully supervised regression classification. Calibration period: years from 2000 to 2014, excluding 2012, which is the validation period. WT38 and WT70 show the atmospheric pattern of the Xynthia (red rectangle) and Joachim (green rectangle) storms, respectively.

This recognition is lost when compared with the WTs identified by SD3 and SD4 models, based on the semi-supervised and non-guided regression classification approaches, respectively (see Section 4.2 and Appendix A, Figures A1-A4). In these cases, only the regional weather patterns are identified, such that the model has a lower performance in classifying extreme events like Xynthia and Joachim as unique or rare events. Instead, these storms are classified as part of other WT, with ordinary surge responses, leading to an underestimated prediction. 


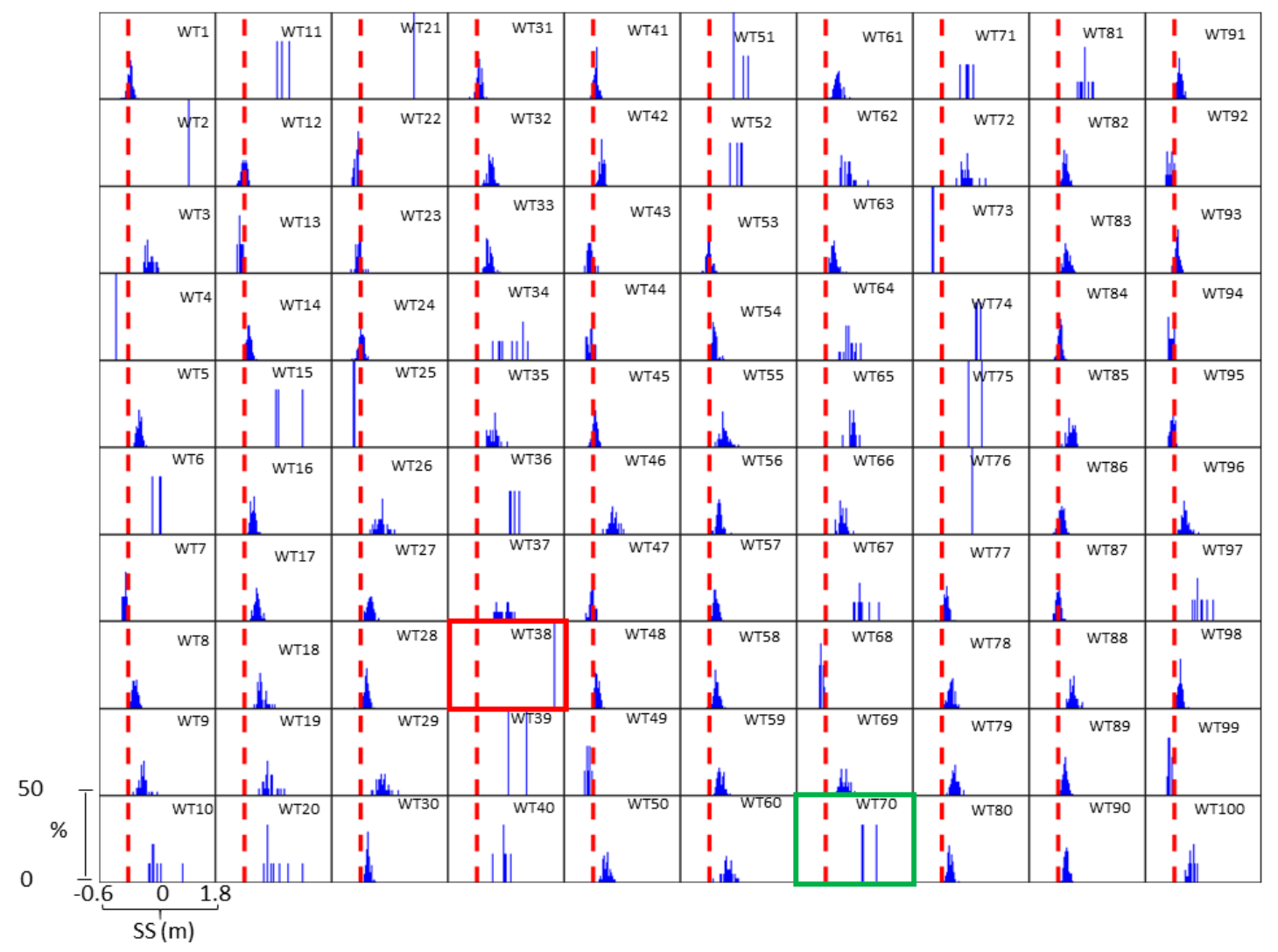

Figure 8. SD1 inferred distribution of daily maximum storm surge (SS) for each SD1 weather type (Figure 7). The dashed red line refers to the value of $0 \mathrm{~m}$. Calibration period: years from 2000 to 2014, excluding 2012, which is the validation period. WT 38 and WT 70 contain the Xynthia (red rectangle) and Joachim (green rectangle) storm surge responses in its associated distribution of SS.

\section{Discussion}

Here, our main findings are compared with former studies (see Section 1 for a description of the main references). First (Section 5.1), we highlight the differences in the optimized SD configuration and the key parameters responsible for its improvement in comparison with other models tested. Second (Section 5.2), we describe the work's main limitations, and also add a discussion about statistical and numerical modeling.

\subsection{Performance of the Optimized Statistical Downscaling}

The optimized SD based on the WT approach (i.e., SD1) for predicting SS at La Rochelle-La Pallice presents a boosted performance in comparison with the ones tested based on former works [12-14], especially for extreme storm surges. This improvement relies on two main parameters combined in the model setup, which are our main findings: the fully supervised classification $(\alpha=1)$, and the predictor (two-day mean of daily minimum SLP and two-day mean of daily maximum SLPG).

The fully supervised classification better distinguishes the WTs associated with the storms responsible for the SS values than the semi or non-supervised approaches do (i.e., SD3 and SD4, respectively). As a consequence, the predictions are improved. Accordingly to a previous work focused on wave and storm surge climate predictions [12], the increment of the parameter $\alpha$ was already suggested as a way to boost results of SDs using the WT framework, especially in areas with a significant influence of local physical processes (e.g., embayed areas and closed seas). In the same study, the value of $\alpha=0.6$ was defined as the best for the North Atlantic domain, being a good balance between a higher model performance and the percentage of the explained predictand's and predictor's variance. 
Despite a similar performance, SD1 overcomes the multilinear regression model (SD2), especially in terms of MAE. Based on $[14,15,28]$, this difference may be related to the limitation of linear regression to properly model the complex predictor-predictand mathematical relationship. In addition, SD1 enables a direct identification of the WTs linked to the extreme storm surge events, while SD2 does not.

Comparing the SD1 model with SD models focusing on wave climate (SD3 and SD4), it is possible to identify some similarities and differences in relation to the predictor configuration. The use of the NA domain and its spatial resolution of $1^{\circ}$ is in agreement with a former work [18]; however, the time window used to define the predictor in the SD1 model relies on the two-day mean, while the SD wave models are based on the three-day mean $[13,18]$. A possible explanation is the fact that the observed SS at La Rochelle mainly results from the atmospheric surges, with a minor contribution from the wave set-up. Indeed, the spin-up of storm surge numerical modeling on the NEA domain lasts one to two days [5], while swells (i.e., the ones which significantly contribute to the regional wave setup) need about three days to travel from the NE generation area to the European Atlantic coast $[33,34]$. Thus, the two-day duration appears as a compromise between these two components.

As in previous studies on weather-type based statistical downscaling for marine variables prediction $[12,13,18]$, we found that by using the K-means algorithm (KMA) initialized by the maximum-dissimilarity algorithm (MDA), the clustering technique ensures a deterministic classification and the most representative initial subset. This technique allows a good statistical representation of the dataset for both average and extreme data. Despite SOM being a good algorithm for visualization of the dataset, we found it was less efficient for statistical description, as also outlined by [39].

\subsection{Limitations}

Although the use of the above characteristics in our SD model has significantly boosted the performance of the weather type statistical downscaling approach, it still has limitations. We worked on one specific site only, La Rochelle, and tidal gauge station, La Rochelle-La Pallice, which has a data availability limitation (only 15 years of continuous data). Thus, it would be interesting to apply the proposed method to other locations and on different time windows, to investigate whether we would reach the same conclusions, and if not, in which case it would differ. In addition, even if improved, the quality of the SD1 prediction remains smaller than what can be expected with the DD approaches. For instance, the numerical modeling study of water level for the Xynthia storm [4] reproduces the daily maximum observed storm surge at La Rochelle-La Pallice tidal gauge station with an error of $\sim 12 \mathrm{~cm}$, while the error of our SD1 model prediction is $\sim 50 \mathrm{~cm}$. It should be noted that this level of precision $(\sim 12 \mathrm{~cm})$ was reached after a significant amount of numerical model improvement to fit the Xynthia storm surge (e.g., including the regional wave set-up, improving the wind stress contribution by including the effect of wave on sea surface roughness). In addition to better precision, such numerical modeling allows for the identifying of the respective contribution of the atmospheric storm surge and wave setup to the storm surges. The numerical solution can thus provide an accurate prediction but at the expense of a large computational time of hours/days, and better distinguish the physical phenomena. However, SD approaches can perform a fast prediction (time computation of minutes) about the most probable SS expected for a given day, hence rapidly providing useful indicators for coastal risk assessment and management, and making feasible any probabilistic approaches as implemented for wave forecasting for instance (see e.g., [17]).

Another complementary information is that, with the SD approaches, it is possible to account for the different phenomena contributing to the storm surge (e.g., in locations where the wave setup contribution is not negligible) in a single model, while DD requires the modeling of each phenomena's contribution to the surge, and thus to know which phenomena are potentially contributing to the surges. Finally, SD approaches require only predictor and predictand data, while DD approaches require atmospheric forcing data (wind and pressure), bathymetric data, seabed roughness data, and sometimes wave conditions, but can predict storm surges anywhere. Both approaches are thus highly complementary, which was also highlighted by [9] for waves. 


\section{Conclusions}

We implemented a statistical downscaling weather type approach for extreme storm surge prediction at La Rochelle-La Pallice tidal gauge, with a focus on daily maxima. First, based on a sensitivity analysis of the various parameters of the weather-type approach, we find that the model configuration providing the best performance in SS prediction relies on a fully supervised classification using minimum daily sea level pressure (SLP) and maximum SLP gradient, with $1^{\circ}$ resolution in the northeast Atlantic domain as the predictor. In comparison with the skills of former SDs, our model leads to an improvement in storm surge prediction, especially for low-probability storms. For instance, in the 2010 year, our model exhibits the smallest RMSE $(0.07 \mathrm{~m})$, while the prediction error of the Xynthia storm surge is reduced by more than $0.5 \mathrm{~m}$. This enhancement is mainly due to the use of the fully supervised regression-guided classification and to the employment of a different predictor (two-day mean of daily minimum SLP and two-day mean of daily maximum SLPG). This process leads to a more detailed discretization of different types of storms that impact the region of La Rochelle, being capable of identifying both regional and local weather types.

Author Contributions: Conceptualization, D.I. and J.R.; methodology, D.I., J.R., W.C., P.C., and M.M.; validation, W.C., D.I., and J.R.; investigation, W.C., D.I., and J.R.; resources, D.I., J.R., P.C., and M.M.; data curation, D.I., J.R., P.C., and M.M.; writing-original draft preparation, W.C.; writing—review and editing, D.I., J.R., P.C., and M.M.; supervision, D.I. and J.R.; project administration, M.M. All authors have read and agreed to the published version of the manuscript.

Funding: This research was funded by the ERA4CS (grant number: 690462). M. Menendez and P. Camus acknowledge the support of the Spanish State Research Agency under the EXCEED project (Grant RTI2018-096449-B-I00).

Acknowledgments: The authors acknowledge G. Le Cozannet for supporting the present work and R. Pedreros for the assistance in meteorological data acquisition for the present work. We extend the acknowledgments also for the institutions that provide high-quality free environment data available such as SHOM, Météo-France, National Ocean-Atmospheric Agency (NOAA). This work is part of the ECLISEA project (https://www.ecliseaproject.eu/).

Conflicts of Interest: The authors declare no conflict of interest.

\section{Appendix A}

Table A1. Average errors of the set-up sensitivity tests for the years 2010 to 2014.

\begin{tabular}{|c|c|c|c|c|}
\hline ID Test & Set-Ups & RMSE (m) & MAE (m) & $\mathbf{R}^{2}$ \\
\hline \multirow{2}{*}{ Domain } & North Atlantic & 0.07 & 0.41 & 0.78 \\
\hline & Northeast Atlantic & 0.09 & 0.58 & 0.68 \\
\hline \multirow{3}{*}{$\begin{array}{c}\text { Spatial } \\
\text { Resolution }\end{array}$} & $2^{\circ} \times 2^{\circ}$ & 0.08 & 0.50 & 0.77 \\
\hline & $1^{\circ} \times 1^{\circ}$ & 0.07 & 0.41 & 0.78 \\
\hline & $0.5^{\circ} \times 0.5^{\circ}$ & 0.09 & 0.57 & 0.69 \\
\hline Number of Days & 2 & 0.07 & 0.41 & 0.78 \\
\hline averaged for the & 3 & 0.08 & 0.53 & 0.73 \\
\hline Predictor Definition & 4 & 0.09 & 0.58 & 0.65 \\
\hline \multirow{2}{*}{ Type of Clustering } & KMA & 0.07 & 0.41 & 0.78 \\
\hline & $\mathrm{SOM}$ & 0.07 & 0.50 & 0.77 \\
\hline \multirow{5}{*}{$\alpha$} & 0.2 & 0.12 & 0.65 & 0.45 \\
\hline & 0.4 & 0.10 & 0.64 & 0.56 \\
\hline & 0.6 & 0.08 & 0.53 & 0.70 \\
\hline & 0.8 & 0.08 & 0.46 & 0.77 \\
\hline & 1 & 0.07 & 0.41 & 0.78 \\
\hline \multirow{4}{*}{ Predictor Variable } & Daily Min. SLP and Daily Max. SLPG & 0.07 & 0.41 & 0.78 \\
\hline & Daily Min. SLP and Daily Max. WND & 0.07 & 0.46 & 0.78 \\
\hline & Daily Mean Geopotential & 0.10 & 0.62 & 0.60 \\
\hline & Daily Max. Geopotential & 0.10 & 0.64 & 0.61 \\
\hline
\end{tabular}




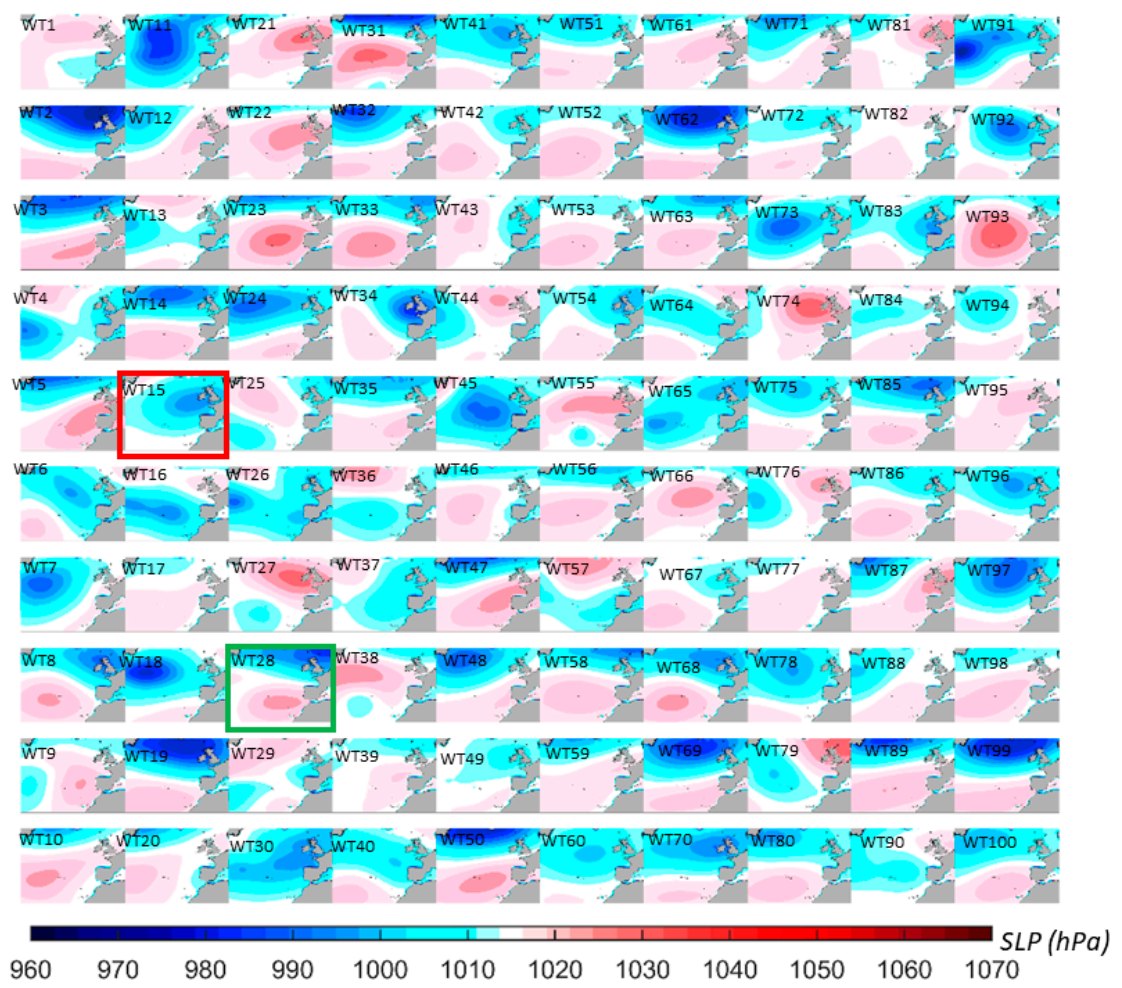

Figure A1. Daily mean SLP associated with each of the 100 weather types of the SD3 model, using a semi-supervised regression classification. Calibration period: years from 2000 to 2014, excluding 2012, which is the validation period. WT 15 and WT28 show the atmospheric pattern of Xynthia (red rectangle) and Joachim (green rectangle) storm, respectively.

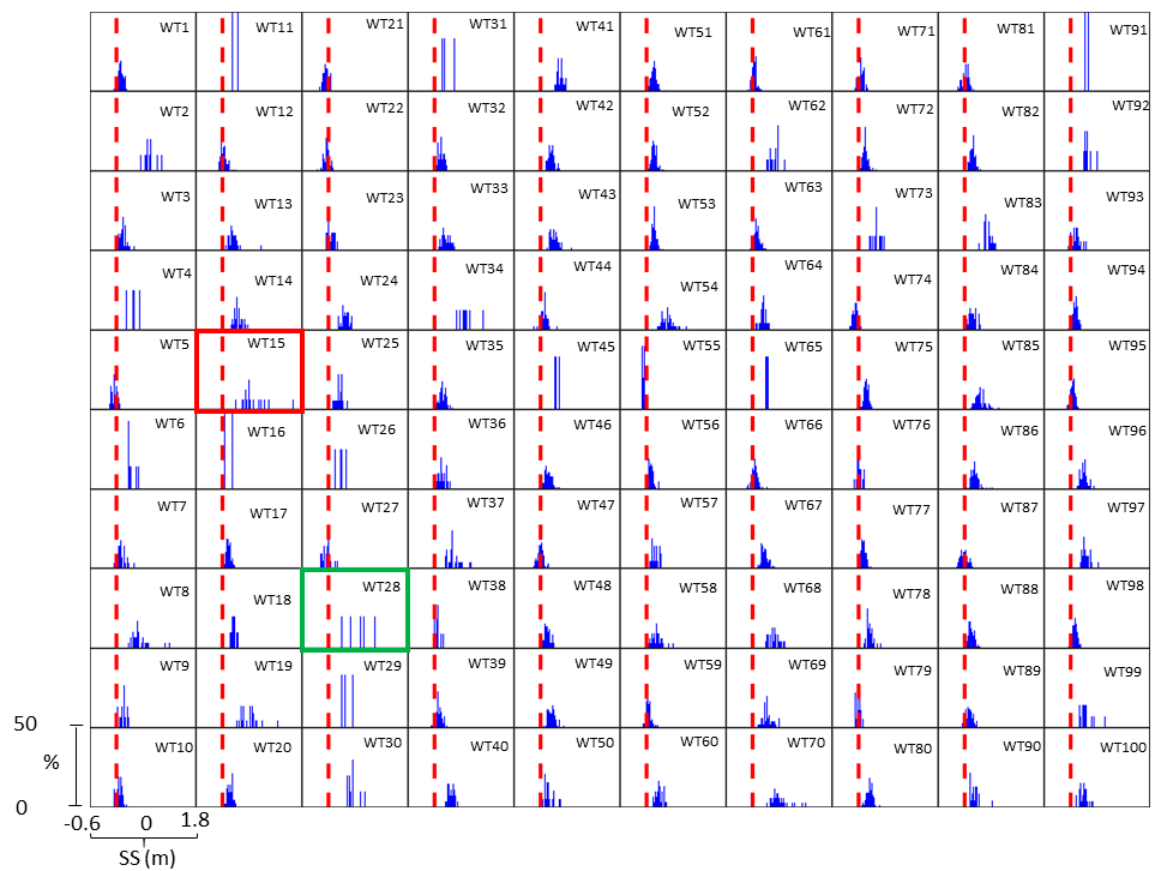

Figure A2. SD3 inferred distribution of daily maximum storm surge (SS) for each SD3 weather type (Figure A1). The dashed red line refers to a value of $0 \mathrm{~m}$. Calibration period: years from 2000 to 2014, excluding 2012, which is the validation period. WT 15 and WT 28 contain the Xynthia (red rectangle) and Joachim (green rectangle) storm surge response in its associated distribution of SS. 


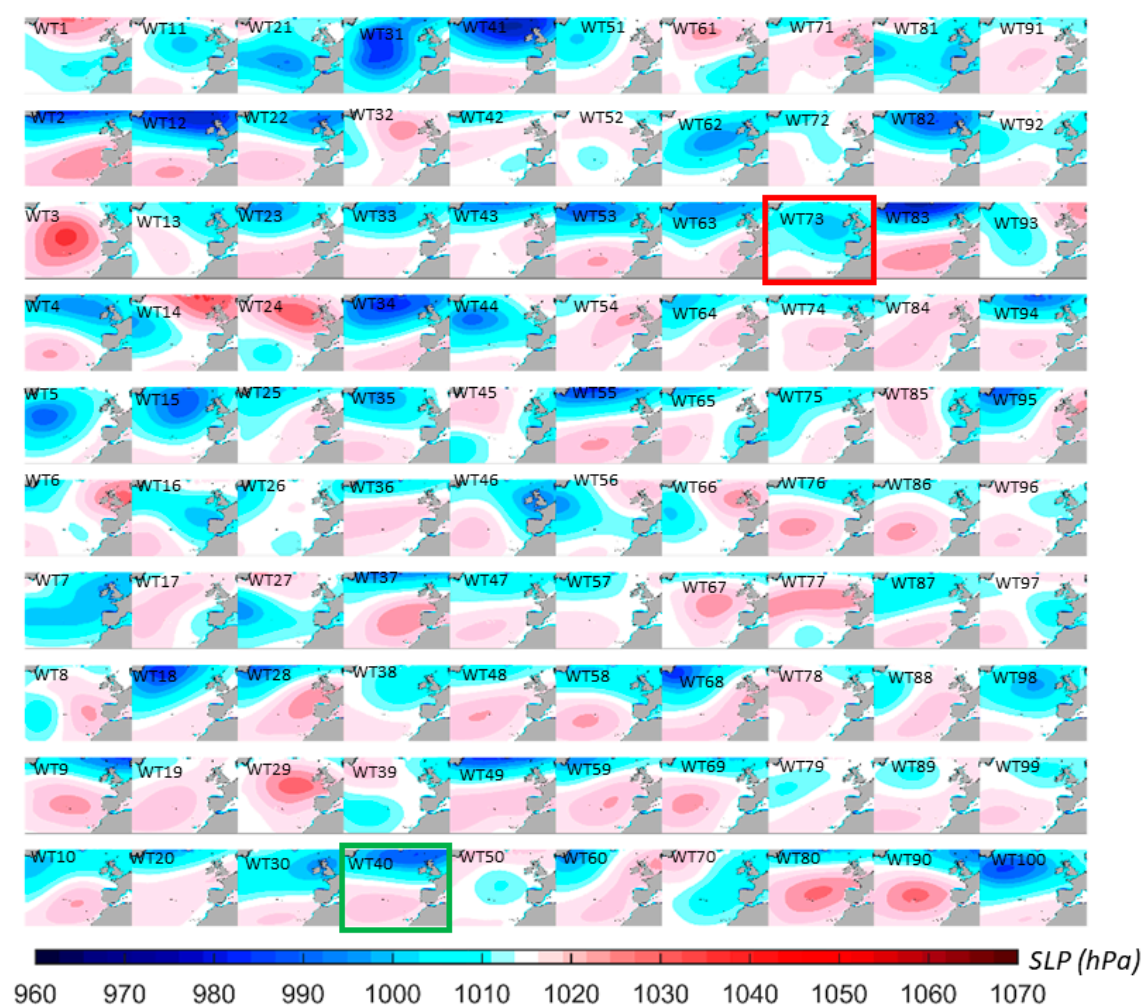

Figure A3. Daily mean SLP associated with each of the 100 weather types of the SD4 model, using a non-guided regression classification. Calibration period: years from 2000 to 2014, excluding 2012, which is the validation period. WT73 and WT40 show the atmospheric pattern of Xynthia (red rectangle) and Joachim (green rectangle) storm, respectively.

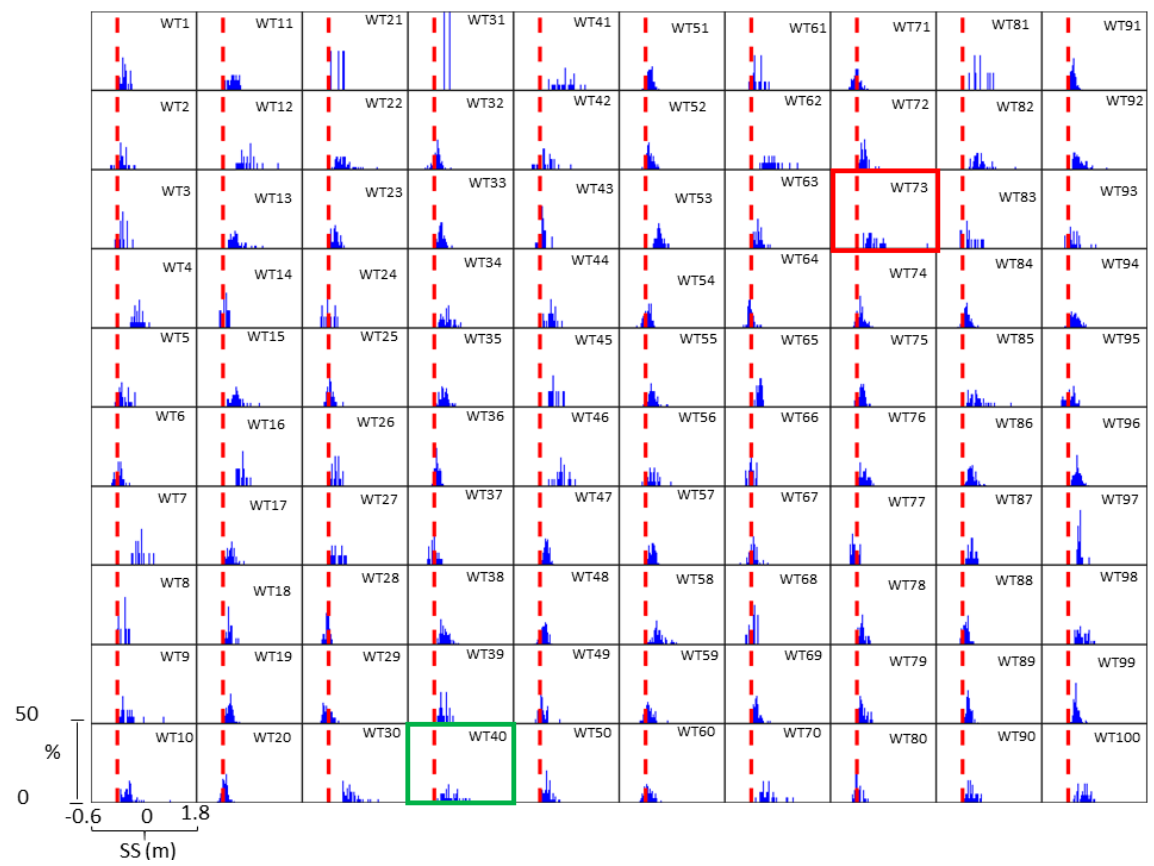

Figure A4. SD4 inferred distribution of daily maximum storm surge (SS) for each SD4 weather type (Figure A3). The dashed red line refers to the value of $0 \mathrm{~m}$. Calibration period: years from 2000 to 2014, excluding 2012, which is the validation period. WT73 and WT 40 contain the Xynthia (red rectangle) and Joachim (green rectangle) storm surge response in its associated distribution of SS. 


\section{References}

1. Gerritsen, H. What happened in 1953? The Big Flood in the Netherlands in retrospect. Philos. Trans. R. Soc. A Math. Phys. Eng. Sci. 2005, 363, 1271-1291. [CrossRef] [PubMed]

2. Von Storch, H.; Gönnert, G.; Meine, M. Storm surges-An option for Hamburg, Germany, to mitigate expected future aggravation of risk. Environ. Sci. Policy 2008, 11, 735-742. [CrossRef]

3. Bertin, X.; Bruneau, N.; Breilh, J.-F.; Fortunato, A.B.; Karpytchev, M. Importance of wave age and resonance in storm surges: The case Xynthia, Bay of Biscay. Ocean. Model. 2012, 42, 16-30. [CrossRef]

4. Bertin, X.; Li, K.; Roland, A.; Bidlot, J.-R. The contribution of short-waves in storm surges: Two case studies in the bay of biscay. Cont. Shelf Res. 2015, 96, 1-15. [CrossRef]

5. Muller, H.; van Rooijen, A.; Idier, D.; Pedreros, R.; Rohmer, J. Assessing storm impact on a French coastal dune system using morphodynamic modeling. J. Coast. Res. 2016, 332, 254-272. [CrossRef]

6. Rohmer, J.; Idier, D.; Paris, F.; Pedreros, R.; Louisor, J. Casting light on forcing and breaching scenarios that lead to marine inundation: Combining numerical simulations with a random-forest classification approach. Environ. Model. Softw. 2018, 104, 64-80. [CrossRef]

7. Pedreros, R.; Dier, D.; Muller, H.; Lecacheux, S.; Paris, F.; Yates-Michelin, M.; Dumas, F.; Pineau-Guillou, L.; Senechal, N. Relative contribution of wave setup to the storm surge: Observations and modeling based analysis in open and protected environments (Truc Vert beach and Tubuai island). J. Coast. Res. 2018. [CrossRef]

8. Idier, D.; Muller, H.; Pedreros, R.; Thiébot, J.; Yates, M.; Créach, R.; Voineson, G.; Dumas, F.; Lecornu, F.; Pineau-Guillou, L.; et al. Système de prévision de surcotes en Manche/Atlantique et Méditerranée: Amélioration du système existant sur la façade Manche/Gascogne [D4]. Rapport final. BRGM/RP-61019-FR. 2012, p. 65. Available online: http://infoterre.brgm.fr/rapports//RP-61019-FR.pdf (accessed on 10 August 2020).

9. Laugel, A.; Menendez, M.; Benoit, M.; Mattarolo, G.; Méndez, F. Wave climate projections along the French coastline: Dynamical versus statistical downscaling methods. Ocean. Model. 2014, 84, 35-50. [CrossRef]

10. Vousdoukas, M.I.; Mentaschi, L.; Voukouvalas, E.; Verlaan, M.; Feyen, L. Extreme sea levels on the rise along Europe's coasts. Earth's Future 2017, 5, 304-323. [CrossRef]

11. Fernández-Montblanc, T.; Vousdoukas, M.I.; Ciavola, P.; Voukouvalas, E.; Mentaschi, L.; Breyiannis, G.; Feyen, L.; Salamon, P. Towards robust pan-European storm surge forecasting. Ocean. Model. 2019, 133, 129-144. [CrossRef]

12. Camus, P.; Rueda, A.; Méndez, F.J.; Losada, I.J. An atmospheric-to-marine synoptic classification for statistical downscaling marine climate. Ocean Dyn. 2016, 66, 1589-1601. [CrossRef]

13. Camus, P.; Menéndez, M.; Méndez, F.J.; Izaguirre, C.; Espejo, A.; Cánovas, V.; Pérez, J.; Rueda, A.; Losada, I.J.; Medina, R. A weather-type statistical downscaling framework for ocean wave climate. J. Geophys. Res. Ocean. 2014, 119, 7389-7405. [CrossRef]

14. Cid, A.; Camus, P.; Castanedo, S.; Méndez, F.J.; Medina, R. Global reconstructed daily surge levels from the 20th Century Reanalysis (1871-2010). Glob. Planet. Chang. 2017, 148, 9-21. [CrossRef]

15. Cid, A.; Wahl, T.; Chambers, D.P.; Muis, S. Storm surge reconstruction and return water level estimation in southeast asia for the 20th century. J. Geophys. Res. Ocean 2018, 123, 437-451. [CrossRef]

16. Cagigal, L.; Rueda, A.; Castanedo, S.; Cid, A.; Perez, J.; Stephens, S.A.; Coco, G.; Méndez, F.J. Historical and future storm surge around New Zealand: From the 19th century to the end of the 21st century. Int. J. Climatol. 2019. [CrossRef]

17. Rueda, A.; Camus, P.; Tomás, A.; Vitousek, S.; Méndez, F.J. A multivariate extreme wave and storm surge climate emulator based on weather patterns. Ocean Model. 2016, 104, 242-251. [CrossRef]

18. Camus, P.; Losada, I.J.; Izaguirre, C.; Espejo, A.; Menéndez, M.; Pérez, J. Statistical wave climate projections for coastal impact assessments. Earth's Futur 2017, 5, 918-933. [CrossRef]

19. Rueda, A.; Cagigal, L.; Antolínez, J.A.; Albuquerque, J.C.; Castanedo, S.; Coco, G.; Méndez, F.J. Marine climate variability based on weather patterns for a complicated island setting: The New Zealand case. Int. J. Climatol. 2019, 39, 1777-1786. [CrossRef]

20. Bezuglov, A.; Blanton, B.; Santiago, R. Multi-output artificial neural network for storm surge prediction in North Carolina. arXiv 2016, arXiv:1609.07378. 
21. Kim, S.W.; Melby, J.A.; Nadal-Caraballo, N.C.; Ratcliff, J. A time-dependent surrogate model for storm surge prediction based on an artificial neural network using high-fidelity synthetic hurricane modeling. Nat. Hazards 2015, 76, 565-585. [CrossRef]

22. Kim, S.-W.; Lee, A.; Mun, J. A surrogate modeling for storm surge prediction using an artificial neural network. J. Coast. Res. 2018, 85, 866-870. [CrossRef]

23. Kim, S.Y.; Matsumi, Y.; Shiozaki, S.; Ota, T. A study of a real-time storm surge forecast system using a neural network at the Sanin Coast, Japan. In Proceedings of the OCEANS 2012 MTS/IEEE: Harnessing the Power of the Ocean, Virginia, NC, USA, 14-19 October 2012. [CrossRef]

24. Lee, T.L. Neural network prediction of a storm surge. Ocean. Eng. 2006, 33, 483-494. [CrossRef]

25. Tseng, C.M.; Jan, C.D.; Wang, J.S.; Wang, C.M. Application of artificial neural networks in typhoon surge forecasting. Ocean. Eng. 2007, 34, 1757-1768. [CrossRef]

26. Bajo, M.; Umgiesser, G. Storm surge forecast through a combination of dynamic and neural network models. Ocean Model. 2010. [CrossRef]

27. Bruneau, N.; Polton, J.; Williams, J.; Holt, J. Estimation of global coastal sea level extremes using neural networks. Environ. Res. Lett. 2020, 15, 074030. [CrossRef]

28. Tadesse, M.; Wahl, T.; Cid, A. Data-Driven Modeling of Global Storm Surges. Front. Mar. Sci. 2020, 7, 1-19. [CrossRef]

29. Dee DPBalmaseda, M.; Balsamo, G.; Engelen, R.; Simmons, A.J.; Thépaut, J.N. Toward a consistent reanalysis of the climate system. Bull. Am. Meteorol. Soc. 2014. [CrossRef]

30. Saha, S.; Moorthi, S.; Pan, H.L.; Wu, X.; Wang, J.; Nadiga, S.; Tripp, P.; Kistler, R.; Woollen, J.; Behringer, D.; et al. The NCEP climate forecast system reanalysis. Bull. Am. Meteorol. Soc. 2010, 91, 1015-1057. [CrossRef]

31. Saha, S.; Moorthi, S.; Wu, X.; Wang, J.; Nadiga, S.; Tripp, P.; Behringer, D.; Hou, Y.T.; Chuang, H.Y.; Iredell, M.; et al. The NCEP climate forecast system version 2. J. Clim. 2014. [CrossRef]

32. SHOM: SHOMAR-Tidal prediction software, Edn. 2014-2015. ISBN 978-2-11-097251-4. 2013.

33. Camus, P.; Méndez, F.J.; Losada, I.J.; Menéndez, M.; Espejo, A.; Pérez, J.; Rueda, A.; Guanche, Y. A method for finding the optimal predictor indices for local wave climate conditions. Ocean Dyn. 2014, 64, 1025-1038. [CrossRef]

34. Pérez, J.; Méndez, F.J.; Menéndez, M.; Losada, I.J. ESTELA: A method for evaluating the source and travel time of the wave energy reaching a local area. Ocean Dyn. 2014, 64, 1181-1191. [CrossRef]

35. Hastie, T. The Elements of Statistical Learning: Data Mining, Inference, and Prediction; Springer: Berlin/Heidelberg, Germany, 2001.

36. Cannon, A.J. Regression-guided clustering: A semisupervised method for circulation-to-environment synoptic classification. J. Appl. Meteorol. Climatol. 2012, 51, 185-190. [CrossRef]

37. Idier, D.; Dumas, F.; Muller, H. Tide-surge interaction in the English Channel. Nat. Hazards Earth Syst. Sci. 2012, 12, 3709-3718. [CrossRef]

38. Kohonen, T. Self-Organizing Maps, Volume 30 of Springer Series in Information Sciences; Springer: Berlin/Heidelberg, Germany, 1997.

39. Camus, P.; Mendez, F.J.; Medina, R.; Cofiño, A.S. Analysis of clustering and selection algorithms for the study of multivariate wave climate. Coast. Eng. 2011. [CrossRef]

Publisher's Note: MDPI stays neutral with regard to jurisdictional claims in published maps and institutional affiliations.

(C) 2020 by the authors. Licensee MDPI, Basel, Switzerland. This article is an open access article distributed under the terms and conditions of the Creative Commons Attribution (CC BY) license (http://creativecommons.org/licenses/by/4.0/). 